\title{
Nephritis, cerebritis, and myositis after adalimumab therapy in a patient with rheumatoid arthritis: a case report
}

This article was published in the following Dove Press journal: International Journal of General Medicine

\author{
Narges E Omran' \\ Abdulsalam A Noorwali ${ }^{2}$ \\ 'Department of Internal Medicine \\ and Rheumatology, Al-Noor Specialist \\ Hospital, Makkah, Saudi Arabia; \\ ${ }^{2}$ Department of Internal Medicine \\ and Rheumatology, Umm Al Qura \\ University Hospital, Makkah, Saudi \\ Arabia
}

\begin{abstract}
Rheumatoid arthritis (RA) is a chronic inflammatory autoimmune disease that mainly affects the joints, therefore, may cause deformities and disability if untreated. The first line of treatment is disease-modifying antirheumatic drugs (DMARDs). When the patient fails to respond to DMARDs, mainly methotrexate, then second-line therapy is required. Tumor necrosis factor $\alpha(\mathrm{TNF} \alpha)$ plays an important role in the pathogenesis of RA; however, the treatment with anti-TNF $\alpha$ medications is challenging. It may trigger the autoimmune system and result in producing antibodies that induce symptoms and signs mimic to systemic lupus erythematosus (SLE), and in rare situations can affect vital organs with severe and life-threatening complications. We report on a 38-year-old Saudi woman with longstanding erosive RA, who was diagnosed based on the 1987 classification criteria. She developed life-threatening SLE, and seroconversion of antinuclear antibodies (ANA), anti-double-stranded DNA, with severe systemic involvement (cerebritis, nephritis, myositis, and polyneuropathy), shortly after treatment with adalimumab. Adalimumab was started as anti TNFa therapy (after the failure of traditional therapy), SLE and other autoimmune diseases were ruled out by clinical history, examination, and laboratory investigations, including negative ANAs and anti-double-stranded DNA. When both tests turned out persistently positive even after stopping adalimumab, specific diagnostic and therapeutic modalities were required during her acute illness.
\end{abstract}

Keywords: rheumatoid, arthritis, tumor necrosis factor, adalimumab, anti-TNF, systemic lupus erythematosus

\section{Introduction}

Early diagnosis and treatment of rheumatoid arthritis (RA) is very important. The use of disease-modifying antirheumatic drugs (DMARDs) during the first few months of the disease minimizes the adverse sequelae of RA. ${ }^{2}$ For non-responders, biological agents are recommended. ${ }^{3}$ Although the treatment with antitumor necrosis factor alpha (anti-TNF $\alpha$ ) had been shown to trigger autoimmune responses, such as a lupus-like syndrome, ${ }^{1}$ the clinical presentation of immune-mediated complications induced by adalimumab treatment, especially a lupus-like syndrome, is very rare, ${ }^{17}$ with various signs and symptoms, including the less common induction of systemic lupus erythematosus (SLE) with end-organ damage. ${ }^{4}$ Written informed consent has been provided by the patient to have the case details and pictures published.
Correspondence: Narges E Omran Department of Internal Medicine and Rheumatology, Al-Noor Specialist Hospital, PO Box 625I, Makkah 21955, Saudi Arabia

Tel +96659442 1399

Email nargesomran@hotmail.com 


\section{Case presentation}

A 38-year-old Saudi woman presented to the emergency department with generalized fatigue and weakness. She had been affected by RA for 13 years, RA was diagnosed based on the 1987 diagnostic criteria, ${ }^{5}$ according to which, the patient had bilateral hand polysymmetric inflammatory arthritis with morning stiffness for more than 1 hour and positive rheumatoid radiographic abnormalities on $\mathrm{X}$ ray (periarticular osteopenia, decreased joint space, and marginal erosions). She developed bilateral hand irreversible deformities within the first 2 years of her disease (ulnar deviation, $\mathrm{Z}$ deformity, swan neck, and boutonniere deformities), with restricted wrists movement and impaired hand grip (Figure 1).

She had no previous history of skin rash, malar rash, muscle weakness, numbness, and no cardiopulmonary symptoms or any symptoms or signs suggestive of SLE or other associated autoimmune diseases.

She was treated for several years with DMARDs; methotrexate $15 \mathrm{mg} /$ week, hydroxychloroquine $200 \mathrm{mg}$ twice daily, and steroid with a maintenance dose of prednisolone 7.5 mg daily (she was given frequent short courses of steroid), as well as calcium, vitamin D, and alendronate. During the course of the treatment, there were periods of remission and flare up. Due to persistent and active inflammatory arthritis for almost 6 months, she was followed up in the rheumatology clinic with the following: number of swollen joints:10; number of tender joints: 15; morning stiffness for more than 1 hour; high erythrocyte sedimentation rate (ESR); and positive C-reactive protein. Her disease activity assessment (28) score of 5.2 meant that she had highly active disease. ${ }^{6}$ Adalimumab was added to her treatment as second-line therapy after the failure of traditional DMARDs based on the American Col-

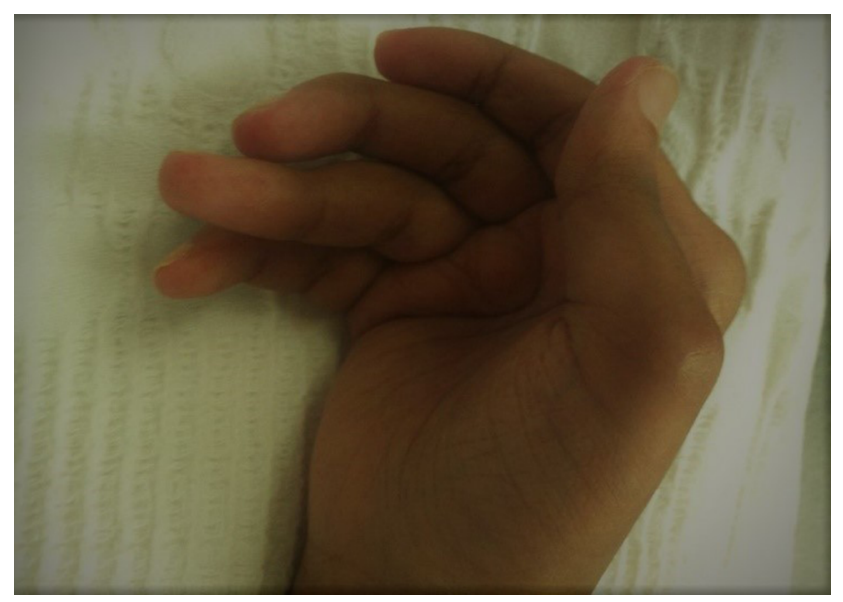

Figure I Rheumatoid arthritis of the hand with deformity. lege of Rheumatology treatment guidelines. ${ }^{3}$ Initial laboratory results showed normal liver and kidney function, mild normocytic normochromic anemia, high ESR of $50 \mathrm{~mm} / \mathrm{h}$, C-reactive protein $4 \mathrm{mg} / \mathrm{dL}$, rheumatoid factor 456 , and anticyclic citrullinated peptide being strongly positive. Hepatitis $\mathrm{B}$ and $\mathrm{C}$ serology were normal, with a negative antinuclear antibody (ANA) of $0.3 \mathrm{IU} / \mathrm{mL}(<1)$, a negative anti-DNA $15 \mathrm{IU} / \mathrm{mL}(<30)$, a negative purified protein derivative test, and normal chest X-ray. Her arthritic symptoms improved dramatically. However, 6 weeks after the administration of adalimumab, she developed fatigue, fever, proximal muscle weakness, and swelling of lower limbs. On examination, she was febrile $\left(38^{\circ} \mathrm{C}\right)$ with normal blood pressure and oxygen saturation. She was conscious, oriented, and had a normal higher function. She had bilateral rheumatoid hands, proximal and distal muscle weakness (grade 2 proximal and grade 3 distal), with depressed reflexes, and decreased pinprick and light touch sensation bilaterally below the knees and distal to the elbows. She had bilateral lower limb pitting edema. Chest and cardiovascular system were normal. The repeat laboratory investigations showed hemoglobin of $8.9 \mathrm{mg} / \mathrm{dL}$, white cell count $7000 / \mu \mathrm{L}$, platelets $170,000 / \mu \mathrm{L}$, ESR $120 \mathrm{~mm} /$ first hour, and C-reactive protein $6.5 \mathrm{mg} / \mathrm{dL}$. Blood chemistry: total protein of $6.1 \mathrm{gm} / \mathrm{dL}$, albumin $2.2 \mathrm{gm} / \mathrm{dL}$, blood urea nitrogen $19 \mathrm{mg} / \mathrm{dL}$, creatinine $0.7 \mathrm{mg} / \mathrm{dL}$, aspartate aminotransferase $410 \mathrm{IU} / \mathrm{L}$, and alanine aminotransferase $90 \mathrm{IU} / \mathrm{L}$. Creatinine kinase was elevated at $5000 \mathrm{IU} / \mathrm{L}$. Urinalysis showed blood +1 and protein +2 . Electromyography and nerve conduction study showed axonal polyneuropathy with myositis. The repeated assessment showed positive ANA of $20 \mathrm{IU} / \mathrm{mL}$, positive anti-dsDNA of $200 \mathrm{IU} / \mathrm{mL}$ (both were negative prior to anti-TNF treatment), positive Smith antibodies, and anti-RNP was negative. Anti-histones test was requested (not available). Complement $\mathrm{C} 3$ was $10 \mathrm{mg} / \mathrm{dL}$ (low), C4 was $5 \mathrm{mg} / \mathrm{dL}$ (low), and 24-hour urine collection for protein showed $650 \mathrm{mg} /$ day. Chest radiography showed bilateral pleural effusion. A diagnosis of SLE with major organ involvement was made based on Systemic Lupus International Collaborating Clinics Classification Criteria. ${ }^{7}$

Adalimumab was discontinued and the patient was administered intravenous methylprednisolone $1 \mathrm{~g}$ daily for 3 days $^{8-10}$ followed by oral prednisolone $1 \mathrm{mg} / \mathrm{kg}$ daily with gradual tapering. During her hospitalization, she developed generalized tonic-clonic seizures. A CT of the brain was normal. An MRI of the brain showed cerebritis. Intravenous immunoglobulin was administered daily for 3 days ${ }^{11,12}$ in addition to antiepileptic medications. Cyclophosphamide was initiated at a dose of $500 \mathrm{mg}$ IV/2 weeks (Euro Protocol) 
as the first-line treatment for lupus nephritis with a plan to continue for 3 months, followed by mycophenolate mofetil as maintenance therapy. ${ }^{8-10}$ The patient was also treated with hydroxychloroquine, angiotensin-converting enzyme inhibitor, aspirin, calcium, and vitamin D replacement. Renal biopsy was performed and showed glomerulonephritis class 4 (Figure 2) according to the World Health Organization's lupus nephritis classification system. ${ }^{13}$

At 6 months, the patient was free of seizures, muscle power was normal, as well as creatine kinase levels. The patient remained ANA and anti-dsDNA positive, with little nephritis improvement in response to first-line therapy. Second-line treatment was begun with mycophenolate mofetil $1500 \mathrm{mg}$ bid. ${ }^{8-10}$

\section{Discussion}

Drug-induced lupus erythematosus (DILE) is an autoimmune disorder that can present with joint pain, skin involvement, fatigue, and serositis.

DILE occurs months after the use of the drug, with subacute cutaneous lupus erythematosus involving the skin being the main manifestation. Hydralazine, procainamide, isoniazid, minocycline, diltiazem, and TNF inhibitors are the most common drugs that cause DILE. Symptoms of DILE usually disappear within weeks of stopping the drug. Generally, no other specific treatments are known. Low doses of systemic corticosteroids may be prescribed for short periods if the symptoms are severe. End-organ damage, such as renal and central nervous system (CNS) involvement, is uncommon in DILE. However, a few drugs that cause DILE are notable exceptions, including hydralazine, penicillamine, and TNF $\alpha$ inhibitors that commonly involve the kidneys. ${ }^{4}$ The patho-

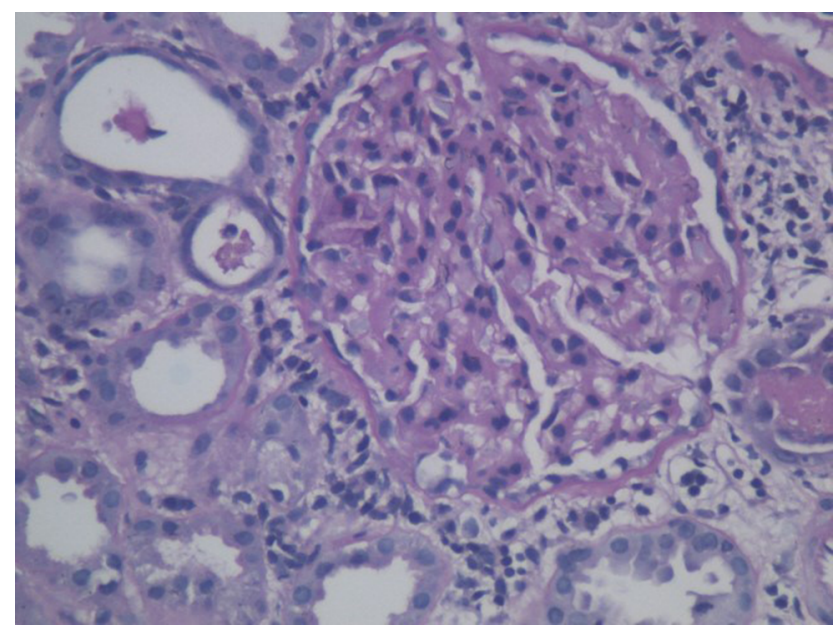

Figure 2 Lupus nephritis: renal biopsy findings. genesis of anti-TNF $\alpha$-induced SLE (ATIL) is not clear. The BIOGEAS Registry collects information on almost 13,000 case reports of patients who developed autoimmune diseases after exposure to biological agents. With >50 different systemic autoimmune disorders, lupus accounts for 369 cases. Anti-TNF agents were the main biologics involved in 9133 cases. Adalimumab was found to be involved in 4154 cases. ${ }^{14}$

For example, one case reported CNS vasculitis after the use of adalimumab for the treatment of Crohn's disease. ${ }^{15}$ Another RA case was reported with lupus nephritis after treatment with adalimumab. ${ }^{16}$ Recently, there was a case report of a patient with severe psoriasis, who presented with muscle pain, paresthesia, and positive ANA following adalimumab treatment. All the symptoms resolved after discontinuation of adalimumab. The main approach in the treatment of ATIL is withdrawal of the offending drug. Symptoms resolve within 3 weeks to 6 months after stopping the drug. Furthermore, many patients require traditional therapy for SLE to achieve full remission. In one registry, about $12 \%$ of patients required additional immunosuppressant medications with azathioprine, cyclophosphamide, leflunomide, methotrexate, mycophenolate, or cyclophosphamide. ${ }^{18}$ It is highly recommended to consider ANA and anti-dsDNA testing to rule out underlying SLE before starting treatment with anti-TNF. ${ }^{17}$ This case report is important because of the severity of the life-threatening multisystem involvement (CNS, peripheral nervous system, kidneys, and muscles) shortly after administration of adalimumab. With documented seroconversion of ANA and anti-dsDNA, special care and additional immunosuppressant therapy were required after discontinuation of adalimumab. The nephritis did not respond well to first-line treatment and required second-line therapy; however, the musculoskeletal and neurological complications resolved completely.

\section{Conclusion}

Autoantibodies are commonly induced by TNF inhibitors but manifest with only limited signs and symptoms. Nevertheless, severe end-organ involvements (cerebritis, nephritis) have been reported to cause serious ATIL. It is highly recommended to test patients for SLE before using anti-TNF therapy to avoid serious complications. Careful observation and follow-up are needed, especially during the first few months of anti-TNF therapy. The pathogenesis of anti-TNF-induced lupus requires further investigation in order to identify those patients who are likely to develop ATIL and related diseases. 


\section{Disclosure}

The authors report no conflicts of interest in this work.

\section{References}

1. Matucci A, Cammelli D, Cantini F, et al. Influence of anti-TNF immunogenicity on safety in rheumatic disease: a narrative review. Expert Opin Drug Saf. 2016;15(Suppl 1):3-10.

2. Schneider M, Krüger K. Rheumatoid arthritis-early diagnosis and disease management. Dtsch Arztebl Int. 2013;110(27-28):477-484.

3. Singh JA, Saag KG, Bridges SL Jr, et al. 2015 American College of Rheumatology Guideline for the treatment of rheumatoid arthritis. Arthritis Rheumatol. 2016;68(1):1-26.

4. Ho CH, Chauhan K. Lupus Erythematosus, Drug-Induced. Treasure Island (FL): StatPearls Publishing; 2017.

5. Arnett FC, Edworthy SM, Bloch DA, et al. The American Rheumatism Association 1987 revised criteria for the classification of rheumatoid arthritis. Arthritis Rheum. 1988;31(3):315-324.

6. van Riel PL. The development of the disease activity score (DAS) and the disease activity score using 28 joint counts (DAS28). Clin Exp Rheumatol. 2014;32(5 Suppl 85):S65-S74.

7. Petri M, Orbai AM, Alarcon GS, et al. Derivation and validation of the Systemic Lupus International Collaborating Clinics classification criteria for systemic lupus erythematosus. Arthritis Rheum. 2012;64(8):2677-2686.

8. Hahn BH, McMahon MA, Wilkinson A, et al; American College of Rheumatology. American College of Rheumatology guidelines for screening, treatment, and management of lupus nephritis. Arthritis Care Res (Hoboken). 2012;64(6):797-808.
9. Ginzler E. Connective tissue diseases: management of lupus nephritis-new guidelines revealed. Nat Rev Rheumatol. 2012;8(10): 565-566.

10. Anders HJ, Appel GB. Lupus nephritis: implications of the new ACR lupus nephritis guidelines. Nat Rev Nephrol. 2012;8(9):500-501.

11. Papo T. [Polyvalent intravenous immunoglobulins in systemic lupus]. Rev Med Interne. 1999;20(Suppl 4):S414-S418. French.

12. Lesprit P, Mouloud F, Bierling P, et al. Prolonged remission of SLEassociated polyradiculoneuropathy after a single course of intravenous immunoglobulin. Scand J Rheumatol. 1996;25(3):177-179.

13. Weening JJ, D'Agati VD, Schwartz MM, et al; Renal Pathology Society Working Group on the Classification of Lupus Nephritis. The classification of glomerulonephritis in systemic lupus erythematosus revisited. Kidney Int. 2004;65(2):521-530.

14. Pérez-De-Lis M, Retamozo S, Flores-Chávez A, et al. Autoimmune diseases induced by biological agents. A review of 12,731 cases (BIOGEAS registry). Expert Opin Drug Saf. 2017;16(11):1255-1271.

15. Vannucchi V, Grazzini M, Pieralli F, Giannotta M, Biagioni C, Nozzoli C. Adalimumab-induced lupus erythematosus with central nervous system involvement in a patient with Crohn's disease. J Gastrointestin Liver Dis. 2011;20(2):201-203.

16. Portuesi MG, Perosa P. [Nephrotic syndrome in a patient with rheumatoid arthritis treated with adalimumab: a case report]. Reumatismo. 2008;60(1):61-63. Italian.

17. Martín JM, Ricart JM, Alcácer J, Rausell N, Arana G. Adalimumabinduced lupus erythematosus. Lupus. 2008;17(7):676-678.

18. Ramos-Casals M, Brito-Zeron P, Munoz S, et al. Autoimmune diseases induced by TNF-targeted therapies analysis of 233 cases. Medicine (Baltimore). 2007;86(4):242-251.
International Journal of General Medicine

\section{Publish your work in this journal}

The International Journal of General Medicine is an international, peer-reviewed open-access journal that focuses on general and internal medicine, pathogenesis, epidemiology, diagnosis, monitoring and treatment protocols. The journal is characterized by the rapid reporting of reviews, original research and clinical studies across all disease areas.

\section{Dovepress}

The manuscript management system is completely online and includes a very quick and fair peer-review system, which is all easy to use. Visit http://www.dovepress.com/testimonials.php to read real quotes from published authors. 